\title{
Özel Kurumlara Ait Huzurevlerinin Mekânsal Risklerinin Fine- Kinney Yöntemi Kullanılarak İncelenmesi: İstanbul Örneği
}

\author{
Zerrin Funda ÜRÜK*, Didem YILMAZ**, Semra BORAN***
}

Öz

Dünya ve Türkiye'deki nüfus hızla yaşlanmakta ve bu yaşlı nüfusun barınma ve bakımı gün geçtikçe önem kazanmaktadır. Yaşlı bireylerin barınma ve bakımları için hizmet veren huzurevleri gibi kuruluşların önemi ve dünya standartlarına uygun hizmet vermesi ülkemizde de gün geçtikçe önem kazanmıştır. Bu çalışmada; huzurevlerinde yaşayan yaşlıların yaşam standartlarını daha iyi bir düzeye çıkarmak amaçlanmıştır. İstanbul ili kapsamında özel kurumlara ait 29 huzurevi incelenmiş, kurumlardan alınan veya birebir mekânlarda tespit edilen veriler sayesinde mekânlardaki ortaya çıkan aksaklıklar değerlendirilmiştir. Çalışma esnasında; huzurevlerinde yaşlı nüfusun sıklıkla kullandıkları mekânlar tespit edilmiş ve 5 ana mekânsal risk tanımlanmış ve bu riskler 47 alt risk grubuna ayrılmıștır. Mekânların alt risk gruplarının her biri Fine-Kinney Risk Değerlendirme yöntemi ile değerlendirilmiş ve en riskli mekânların verilerine ulaşılmıştır. Çalışma sonucunda, İstanbul'daki huzurevlerinde yaşayan yaşlı bireylerin yaşam standartlarını daha iyi bir düzeye çıkarmak için mekânlardaki risklere göre dikkat etmemiz gereken alanları tespit edip, mekânların iyileştirmeleri için öneriler sunulmuştur.

Anahtar Kelimeler: Huzurevleri, Tasarım, Erișebilirlik, Risk Değerlendirilmesi, Fine-Kinney

\author{
Özgün Araștırma Makalesi (Original Research Article) \\ Geliş/Received: 08.10 .2018 \\ Kabul/Accepted: 22.01 .2019 \\ DOI: http://dx.doi.org/10.17336/igusbd.455165 \\ * Dr. Öğr. Üyesi, İstanbul Gelişim Üniversitesi, Güzel Sanatlar Fakültesi, İç Mimarlık ve Çevre \\ Tasarımı Bölümü, İstanbul, Türkiye, E-posta: zfuruk@gelisim.edu.tr \\ ORCID ID https://orcid.org/0000-0002-3994-5883 \\ ${ }^{* *}$ Dr. Öğr. Üyesi, İstanbul Gelişim Üniversitesi, Mühendislik ve Mimarlık Fakültesi, Endüstri \\ Mühendisliği Bölümü, İstanbul, Türkiye, E-posta: dyilmaz@gelisim.edu.tr \\ ORCID ID https://orcid.org/0000-0002-4971-4931 \\ *** Doç. Dr., Sakarya Üniversitesi, Endüstri Mühendisliği Bölümü, Sakarya, Türkiye, \\ E-posta: boran@sakarya.edu.tr ORCID ID https://orcid.org/0000-0002-0532-937X
}




\title{
Investigation of Spatial Risks of Private Nursing Home Institutions by Using Fine-Kinney Method: The Case of Istanbul
}

\begin{abstract}
Rapidly aging population in the World and inTurkey and sheltering and care of the elderly population is gaining importance day by day. It has become increasingly important in our country to provide services such as nursing homes that provide services for the care and maintenance of elderly people in accordance with world standards. In this study; it is aimed to bring the living standards of elderly people living in nursing homes to a better level. Within the Istanbul province, 29 nursing homes belonging to private institutions were examined and deficiencies the risks in the areas were identified later indoor plans taken from institutions or drawn after observations. During work; In the nursing homes, the places where the elderly population frequently used are identified and 5 main spatial risks are identified and these risks are divided into 47 sub-risk groups. Each of the sub-risk groups of the space was assessed by the Fine-Kinney Risk Assessment method and the data of the most risky places were reached. As a result of the study, in order to improve the living standards of elderly people living in nursing homes in Istanbul, we have identified the areas that we should not pay attention to according to the risks in the rooms and offered suggestions for the improvement of the spaces.
\end{abstract}

Keywords: Nursing homes, Design, Accessibility, Risk Assessment, Fine-Kinney

\section{Giriş}

“Toplumların yaşlanması” yirminci yüzyılda hızlıca gelișen bir kavram olmuştur. Gelişmiş Dünya ülkeleri arasında yaşlılık önemli bir yer teşkil ederken, günümüzde ülkemizde de gün geçtikçe artan bir gerçeklik olmaya başlamıştır. Son dönemlerdeki nüfus artış hızındaki azalma ve ortalama yaşam sürecinin artması sonucu dünyamız giderek demografik yașlanma sürecine girmektedir. Yaşlı nüfusun artışı yılda \%2,5 oranında bir yükseliş ile devam etmektedir. Bugün dünya üzerindeki toplam nüfusun yüzde 10'u 65 ve daha yukarı yaşlardaki nüfusu oluștururken 2050'de bu oranın yüzde 16'nın üzerine çıkması beklenmektedir (Devlet Planlama Teşkilatı [DPT], 2007, s. 6). Dünya Sağlık Örgütü (DSÖ)'nün yaşlanma ile ilgili 1963 yılında yapmış olduğu kronolojik sınıflandırmaya göre; Orta yaş 45-59 yaş arasında, Yaşlılık 60-74 yaş arasında, İleri yaşlılık 75-89 yaş arasında ve İhtiyarlık ise 90 ve üstü yaş arasında yer almıştır.

\section{Dünyada ve Türkiye'de Yaşlılık}

Dünyada en hızlı büyüyen yașlı grubu 80 yaş ve üstüdür. 2000 yılında bu gruptaki yaşlı bireylerin sayısı 70 milyon iken, önümüzdeki 50 yıl içinde bu sayının 5 katından daha fazla artacağı beklenmektedir. 21. yüzyılın ilk yarısından itibaren hızla 
Zerrin Funda Ürük, Didem Yllmaz, Semra Boran, “Özel Kurumlara Ait Huzurevlerinin Mekânsal Risklerinin FineKinney Yöntemi Kullanılarak İncelenmesi: İstanbul Örneği”, İstanbul Gelişim Üniversitesi Sosyal Bilimler Dergisi, 6 (1), Nisan 2019, ss. 102-119

yaşlanan nüfustaki yaşlı kișilerin oranı Şekil 1 ‘de gösterildiği üzere 2050 yılında \%8'lik dilimden \%19’luk dilime çıkması beklenmektedir.

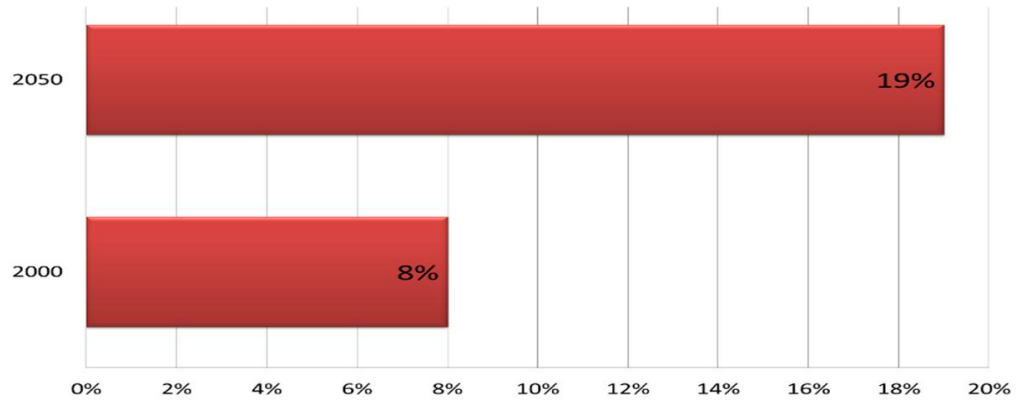

Şekil 1: Dünya'da ki yaşlı kişilerin 2050 yılındaki nüfus artış oranı

Bu oranların getirisi olarak, neredeyse gelişmiș ülkelerin tümü ileriki senelerde nüfuslarının yaşlanması ile karşı karşıya kalacaklardır. Dünya Sağlık Örgütünün (2015) belirttiği ve Şekil 2'de de görüleceği üzere yaşlı nüfusun "yaşlıların yaşlanması” olarak adlandırılan bir süreci bașlatacağı ön görülmüștür.
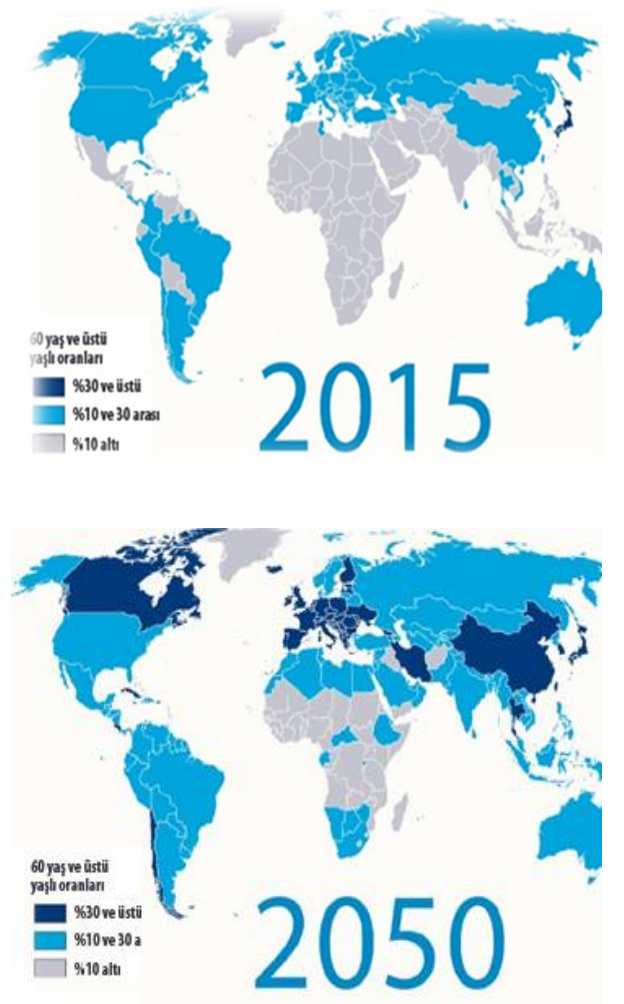

Kaynak: WHO 2015

Şekil 2: Dünya 60 yaş + nüfus artışı (2015 ve 2050 yılları arası) 
Nüfusun yaşlanması, nüfusun yaş yapısının değișerek, o nüfustaki çocuklara ve gençlere ait olan yaş gruplarını oranının azalması ve 65 yaş üstü yaşlı bireylerin oranının belirgin ölçüde artması demektir. Ülkemizde yaşlı nüfus oranı 1990’lara kadar \%5'in altında iken son 15 yıl içinde dünyada da gözlemlenen artışla doğru orantılı olarak, ciddi bir artış eğilimi içerisine girmiştir ve Tablo 1'de görüleceği üzere ülkemiz tarihinin en yüksek noktasına ulaşmıș durumdadır.

\begin{tabular}{|lll|l|l|}
\hline Yll & \multicolumn{1}{l}{$\begin{array}{l}\text { Toplam } \\
\text { Nüfus }\end{array}$} & \multicolumn{3}{l}{ Yaş Grupları (\%) } \\
\cline { 3 - 5 } & 16.158 .018 & $0-14$ Yaş & $15-65$ Yaş & $65+$ Yaş \\
\hline 1935 & 79.814 .871 & 41,4 & 54,7 & 3,9 \\
\hline 2016 & 23,7 & 68,0 & 8,3 \\
\hline
\end{tabular}

Kaynak: TÜIK, 2017

Tablo 1: Türkiye'de yaş gruplarının toplam nüfus içindeki dağılımı (1935-2016)

Birleşmiş Milletler 'in bir ülkeyi yaşlı nüfus olarak tanımlayabilmesi için; o ülkedeki yaşlı bireylerin toplam nüfus içindeki oranının \%15'ini geçmesi gerekmektedir. Bir ülkenin yaşlı nüfusunun genel nüfus oranına göre $\% 8$ ve $\% 10$ aralarında olması o ülkenin "yașlı" nüfuslu bir ülke olduğunu gösterdiği olduğu gibi, oranın \%10'un üzerine çıkması "çok yaşlı" nüfuslu ülke olmaya aday olduğunun göstergesidir. Türkiye İstatistik Kurumunun (2014) ülkemizin nüfus verilerine göre; 65 yaş üstü kişilerin genel nüfus oranları Şekil 3' de görüleceği üzere, 1935 yılında oranlar \%3,9 iken, 1990 yılında \%4,3 seviyelerine ve akabinde 2016 yılında \%8,3' e yükselmekle beraber 2023 yılında hızla artarak \%10,2'ye yükseleceği öngörülmektedir. 2050 yılında ise bu oranların \%17,5'leri bularak "çok yaşlı" nüfuslu ülkeler arasında Türkiye'nin de yer alacağı tahmin edilmektedir.

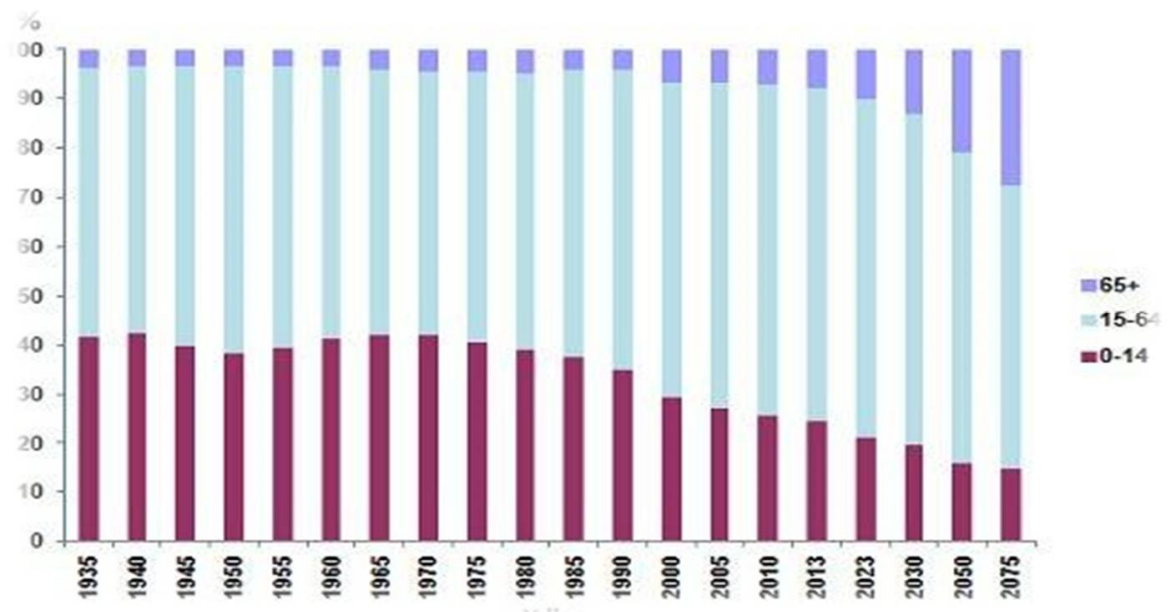

Kaynak: TÜIK, 2014

Şekil 3: Türkiye yaş yapısı değişimi (1935-2075) 


\section{Türkiye’de Yaşlılara Yönelik Sosyal Hizmetler; Huzurevleri ve Bakımevleri}

Engelli ve Yaşlı Hizmetleri Genel Müdürlüğü'nün (2017) belirttiği gibi, yaşlılara yönelik iki ayrı kuruluşta sosyal hizmetler verilmektedir. Bunlardan biri olan Huzurevlerinde; +60 yaş ve üzerindeki yaşlı kişileri huzurlu bir ortamda korumak, bakımını sağlamak ve sosyal ve psikolojik ihtiyaçlarını karşılamak amacıyla kurulan yatılı sosyal hizmet kuruluşlardır. Bir diğer kuruluş ise; Yaşlı bakım ve rehabilitasyon merkezleridir. Bu merkezler, yaşlı bireylerin geri kalan yaşamlarını sağlıklı, huzurlu ve güvenli şekilde sürdürmeleri ve kendi kendilerini idare edebilecek şekilde rehabilitasyonlarının sağlanabildiği, tedavisi mümkün olmayanların ise sürekli olarak özel bakım altına alındığı yerlerdir.

Huzurevleri, yaşlının yıllardır kendi düzenlerinde sürdürdüğü ve alışık olduğu aile ortamlarından sonra günlük yaşamlarını sürdüreceği sosyal hizmet veren bir kuruluştur. Toplumun kentsel gelişim sürecinde, sosyal ve ekonomik olarak hızlıca değişmesi ile pek çok yaşlı bireyin yaşamlarının geri kalan bölümlerini huzurevlerinde geçirmek durumunda bırakmaktadır.

65 yaş üstü bireylerin çoğu sağlıklı ve gündelik yaşantılarında yardıma ihtiyaç duymayan bireyler olmasına rağmen 65 yaş üstü bireylerde yapılan araștırmalarda; 65 ile 69 yaş arasındaki yaşlıların tam günlük bakım ihtiyaçlarının karşılayabilme oranı \%5'in altında gözükürken, 80 ve üstü yaşlılarda tam günlük bakım ihtiyaçlarının oranı \%30'a kadar çıkmaktadır.

Ülkemizde bulunan huzurevlerinin Eylül 2016 itibari ile sayıları 367'e ulaşmış ve doluluk oranları Tablo 2 de belirtildiği gibi \%80 civarında olmuştur. Ülkemizin büyük yerleşim bölgelerinden biri olan İstanbul'daki huzurevi sayısı ise Tablo 3'de görüleceği gibi Türkiye genelindeki huzurevi sayınının \%30'luk diliminin karşılamaktadır.

\begin{tabular}{|l|l|l|l|}
\hline $\begin{array}{l}\text { TÜRKIYE GENELINDE HUZUREVLERİ ve } \\
\text { BAKIMEVLERI }\end{array}$ & Sayı & Kapasite & Doluluk Oranı \\
\hline $\begin{array}{l}\text { Aile ve Sosyal Politikalar Bakanlığı } \\
\text { Özürlü ve Yaşlı Hizmetleri Genel } \\
\text { Müdürlüğüne Bağı Huzurevleri }\end{array}$ & 140 & 14.439 & 12.926 \\
\hline Yaşıı Yaşam evleri & 41 & 160 & 154 \\
\hline Diğer Bakanlıklara Bağlı Huzurevleri & 2 & 570 & 566 \\
\hline Belediyelere Ait Huzurevleri & 21 & 2.977 & 2.083 \\
\hline Dernek ve Vakıflara Ait Huzurevleri & 29 & 2.435 & 1.704 \\
\hline Azınlıklara Ait Huzurevleri & 5 & 508 & 355 \\
\hline Özel Huzurevleri & 170 & 9.501 & 6.650 \\
\hline TOPLAM & 367 & 30.590 & 24.438 \\
\hline
\end{tabular}

Kaynak: Aile ve Sosyal Politikalar Bakanlı̆̆ı

Tablo 2: Türkiye Genelinde Huzurevlerinin Sayı-Kapasite-Doluluk Oranları (2016) 


\begin{tabular}{|l|l|l|}
\hline $\begin{array}{l}\text { ISTANBUL GENELİNDE HUZUREVLERİ ve } \\
\text { BAKIMEVLERİ }\end{array}$ & Sayı & \multicolumn{2}{l}{ Kapasite } \\
\hline $\begin{array}{l}\text { Aile ve Sosyal Politikalar Bakanlığı Özürlü ve Yaşlı } \\
\text { Hizmetleri Genel Müdürlüğüne Bağlı Huzurevleri }\end{array}$ & 9 & 1.538 \\
\hline Diğer Bakanlıklara Bağlı Huzurevleri & 2 & 570 \\
\hline Belediyelere Ait Huzurevleri & 3 & 1.026 \\
\hline Dernek ve Vakıflara Ait Huzurevleri & 12 & 1.080 \\
\hline Azınlıklara Ait Huzurevleri & 5 & 508 \\
\hline Özel Huzurevleri & 75 & 4.457 \\
\hline TOPLAM & $\mathbf{1 0 6}$ & $\mathbf{9 . 1 7 9}$ \\
\hline
\end{tabular}

Kaynak: Aile ve Sosyal Politikalar Bakanlı̆̆ı

Tablo 3: İstanbul Genelinde Bulunan Huzurevlerinin Sayı ve Kapasiteleri (2016)

\section{Araștırmanın Amacı ve Yöntem}

Huzurevleri yaşlıların günlük ihtiyaçlarının karşılandığı ve adeta onların evleri haline gelen yaşam mekânlarıdır. Bu kurumlar; yaşlı bireylerin günlük gereksinimleri, kişisel bakımı, oda temizliği, yemeği vb. ihtiyaçlarının yanı sıra sosyalleştiği, sağlık ve tedavi gibi olanakların sağlandığı merkezlerdir. Bu nedenle huzurevinin kalitesi yaşlının yaşam kalitesinin göstergesidir. Ancak yapılan araştırmalar, yaşlıların yaşam kalitesini sürdürmek için sunulan bu hizmetlerin söz konusu merkezlerde çok yeterli olmadığını göstermektedir. (Zerrin Funda Ürük ve Didem Yılmaz, kişisel görüşme, Nisan 2017)

$\mathrm{Bu}$ araştırmada; Aile ve Sosyal Politikalar Bakanlığı bünyesinde, İstanbul Bölgesindeki özel kurumlara ait huzurevlerinin mekânsal risk alanları sınıflandırılarak ele alınmış, elde edilen veriler Fine- Kinney yöntemine göre değerlendirilmiş ve yaşlıların yaşam kalitesini sürdürmek için bu riskleri azaltmaya ait önlemler önerilmiştir.

$\mathrm{Bu}$ çerçevede ele alınan veriler doğrultusunda 1230 kişi ile çalışılmıştır. $\mathrm{Bu}$ örneklem içerisinde 869 kadın ve 361 erkektir. Huzurevleri ve bakımevlerine gelen kişilerin yaş ortalaması 74'dür. Genel yaşlı nüfusun standart sapması ise 5,767'dir. Kadınların yaş ortalaması 77,8 standart sapması 5,85 ve erkeklerin ortalaması 71,8 ve standart sapması 6,39 olarak bulunmuştur. Huzurevi ve bakımevlerinde kalan yaşlı bireylerin 68,1-79,7 yaş aralığında olduğu tespit edilmiştir. İstanbul ili içinde ve yakın çevresinde yer alan 29 huzurevi ve yaşlı bakım evi çerçevesinde elde edilen verilerin dağılımı ise Tablo 4 de özetlenmiştir. 


\begin{tabular}{|l|l|l|l|l|l|}
\hline CINSIYET & & $\begin{array}{l}\text { Huzurevi } \\
\text { Yaşlı } \\
\text { Bakımevi }\end{array}$ & Yüzdesi \% & Toplam & Yüzdesi \% \\
\hline KADIN & $\mathbf{6 5}$ yaş altı & 39 & 4,5 & 869 & 70.6 \\
\hline KADIN & $\mathbf{6 5}$ yaş üstü & 830 & 95,5 & & \\
\hline ERKEK & $\mathbf{6 5}$ yaş altı & 37 & 10,2 & 361 & 29.4 \\
\hline ERKEK & $\mathbf{6 5}$ yaşüstü & 324 & 89,8 & & \\
\hline
\end{tabular}

Tablo 4: İstanbul ve yakın çevredeki Huzurevi ve Yaşlı bakımevi kalan kişilerin sayı ve yüzdeleri (Haziran 2017)

\section{Bulgular}

Huzurevinde yapılan incelemeler sonucu tahmini risk oluşturabilecek mekânlar 5 ana risk grubunda toplanmıştır. Bu ana gruplarda kendi içinde 47 alt risk grubuna ayrılarak Fine- Kinney yöntemine göre değerlendirme yapılmıştır.

Ana Risk grupları;

a) Merdiven- Asansörler

b) Wc-Banyo

c) Koridorlar

d) Odalar

e) Sosyal Alanlar

Fine-Kinney Risk analizi yöntemi; "Mathematical Evaluations for Controlling Hazards" olarak bilinen ve revize edilerek "Practical Risk Analysis for Safety Management" günümüze kadar gelmiş yaygın risk değerlendirme yöntemlerindendir. Bir riskin zaman içinde gerçekleşme olasılığı (olasılık), riske maruz kalma sıklığı (frekans) ve riskin gerçekleşmesi sonucunda ortaya çıkaracağı zarar (şiddet) derecesi gibi üç faktör değerlendirilerek risk ölçüm değeri (RÖS) bulunur.

Fine-Kinney Risk analizi yöntemi, kurumların geçmiş verileri ve öngörülerini bir arada kullanma imkânı veren kalitatif bir yöntemdir. Bu analiz yöntemi sadece tehlike olma olasılığını ve sıklığını değil, tehlike (risk) altındaki kişilerin tehlikeli alanlarda bulunma ve/veya tehlikeye maruz kalma sıklığını da dikkate aldığından ötürü diğer risk analizi yöntemlerine göre daha güvenilir ve doğru analiz yapma imkânı sağlamaktadır. Fine- Kinney yöntemi; risklerin derecelendirilmesi ve sonuçlarına göre hangi risklerin iyileștirilmesine öncelik verileceğini ve kaynakların öncelikli olarak nereye aktarılması gerektiğini gösteren bir yöntemdir.

Fine-Kinney Risk analizi değerlendirilmesi; Olasılık, Şiddet ve Frekans skalalarından meydana gelmiștir.

RÖS= Olasılık x Frekans $x$ Şiddet cinsinden hesaplanır.

Olasılık; oluşabilecek riskin zaman içinde gerçekleşme olasılığıdır. 0,2 ile 10 arasındaki olasılık değerleri Tablo 5'de görülmektedir. 
Zerrin Funda Ürük, Didem Yllmaz, Semra Boran, “Özel Kurumlara Ait Huzurevlerinin Mekânsal Risklerinin FineKinney Yöntemi Kullanılarak İncelenmesi: İstanbul Örneği”, İstanbul Gelişim Üniversitesi Sosyal Bilimler Dergisi, 6 (1), Nisan 2019, ss. 102-119

\begin{tabular}{|c|l|}
\hline OLASILIK DEĞERİ & $\begin{array}{l}\text { OLASILIK } \\
\text { Riskin gerçekleşme olasılığı }\end{array}$ \\
\hline 10 & Çok kuvvetli olasılık \\
\hline 6 & Kuvvetle olasılık \\
\hline 3 & Nadir fakat olabilir \\
\hline 1 & Oldukça düşük olasıllk \\
\hline 0,5 & Zayıf olasıllk \\
\hline 0,2 & Pratik olarak imkânsız \\
\hline
\end{tabular}

Tablo 5: Olasılık değerleri ve riskin gerçekleşme olasılığı tablosu

Frekans; Riske zaman içinde maruz kalma tekrarıdır. 0,5 ile 10 arasındaki frekans değerleri Tablo 6'de görülmektedir.

\begin{tabular}{|c|l|l|}
\hline $\begin{array}{c}\text { FREKANS } \\
\text { DEĞERI }\end{array}$ & $\begin{array}{l}\text { FREKANS } \\
\text { riske zaman içinde maruz kalma tekrarı }\end{array}$ \\
\hline 10 & Sürekli & Sürekli ya da saatte birden fazla \\
\hline 6 & Slklıkla & Günde bir ya da birkaç kez \\
\hline 3 & Ara sıra & Haftada bir ya da birkaç kez \\
\hline 2 & Nadir & Ayda bir ya da birkaç kez \\
\hline 1 & Oldukça nadir & Yılda bir ya da birkaç kez \\
\hline 0,5 & Çok nadir & Yılda bir ya da daha az \\
\hline
\end{tabular}

Tablo 6: Frekans değerleri ve riske zaman içinde maruz kalma tekrarı tablosu

Şiddet; Riskin veya tehlikenin kişi üzerinde yaratacağı zarardır. Ölüm veya toplu ölümler, ağır yaralanmalar vs. Şiddet değerleri 1 ile 100 arasındadır. 
Zerrin Funda Ürük, Didem Yllmaz, Semra Boran, “Özel Kurumlara Ait Huzurevlerinin Mekânsal Risklerinin FineKinney Yöntemi Kullanılarak İncelenmesi: İstanbul Örn eği”, İstanbul Gelişim Üniversitesi Sosyal Bilimler Dergisi, 6 (1), Nisan 2019, ss. 102-119

\begin{tabular}{|c|l|}
\hline ŞIDDET & ŞIDDET \\
DEĞERİ & insan üzerinde yaratacağı tahmini zarar \\
\hline 100 & Birden çok ölüme sebep olan ciddi problem \\
\hline 40 & Çok çok Önemli (ölümle sonuçlanan çok ciddi yaralanma) \\
\hline 15 & Çok önemli (uzuv kaybı, kalıcı sakatlık) \\
\hline 7 & Önemli (ciddi yaralanma) \\
\hline 3 & Az Önemli (küçük hasar, ilkyardıma ihtiyaç duyma) \\
\hline 1 & Önemsiz (yaralanmaya yol açmayan) \\
\hline
\end{tabular}

Tablo 7: Şiddet değerleri ve insan üzerinde yaratacağı tahmini zarar tablosu

Çalışması yapılan huzurevlerinde Risklerin gerçekleșeceği beş ana mekânlardaki Olasılık, Frekans, Şiddet değerlerinin beraberindeki Risk Değerlerinin gözüktüğü FineKinney Risk Değerlendirme sonucu Tablo 8 de özetlenmiştir. Tablo 9 da ise RÖS değerlerini bulmak için yapılan Matris Tablosu özetlenmiştir.

\begin{tabular}{|l|l|}
\hline RISK DEĞERI & RISK DEĞERLENDIRME SONUCU \\
\hline $400=<$ RÖS & $\begin{array}{l}\text { çok yüksek risk } \\
\text { hemen gerekli önlemler alınmalı }\end{array}$ \\
\hline $200=<$ RÖS $<400$ & $\begin{array}{l}\text { yüksek risk } \\
\text { kısa dönemde iyileştirilmelidir (birkaç ay içinde) }\end{array}$ \\
\hline $70=<$ RöS $<200$ & $\begin{array}{l}\text { orta risk } \\
\text { uzun dönemde iyileştirilmelidir (yıl içinde) }\end{array}$ \\
\hline $20=<$ RÖS $<70$ & $\begin{array}{l}\text { düşük risk } \\
\text { gözetim altında uygulanmalıdır }\end{array}$ \\
\hline RÖS $<20$ & $\begin{array}{l}\text { çok düşük risk } \\
\text { önlem öncelikli değildir }\end{array}$ \\
\hline
\end{tabular}

Tablo 8: Fine-Kinney Risk Değerlendirme Tablosu 


\begin{tabular}{|c|c|c|c|c|c|c|}
\hline & \multicolumn{6}{|c|}{ FREKANS } \\
\hline & 0,5 & 1 & 2 & 3 & 6 & 10 \\
\hline \multirow{6}{*}{ 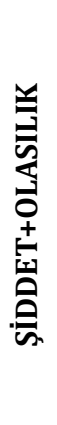 } & 0,1 & 0,6 & 2,8 & 9 & 48 & 200 \\
\hline & 0,25 & 1,5 & 7 & 22,5 & 120 & 500 \\
\hline & 0,5 & 3 & 14 & 45 & 240 & 1000 \\
\hline & 1,5 & 9 & 42 & 135 & 720 & 1000 \\
\hline & 3 & 18 & 84 & 270 & 1440 & 6000 \\
\hline & 5 & 30 & 140 & 450 & 2400 & 10000 \\
\hline
\end{tabular}

Tablo 9: RÖS değerlerinin Matris Tablosu

Merdiven ve asansör tablosunda görüleceği üzere; mekânsal analizde en riskli bölgeler WC-Banyo ve Merdiven-Asansör olarak bulunmuştur. Merdiven-Asansörlerde toplam 10 adet riskli alt bölge için yöntem uygulandığında 4 riskli alt bölge RÖS 400'den büyük çıktığı için öncelikli risk sınıfına girmekte ve bu riskler giderilmezse ölümle sonuçlanabilecek neticeler verebileceği için acil olarak ele alınması gerekmektedir.

Örneğin; Merdiven ve asansörler mekânı içindeki bir tehlike olan, basamakların uygun malzemeden yapılmaması ile ortaya çıkan risk/etki olarak, yaşlı bireyin dengesini kaybederek düşme neticesindeki ölüm ve ağır yaralanma sonucu RÖS=1400 çıktığı için RÖS $\geq 400$ sınırını aştığından kırmızı ile işaretlenmiştir. Yapılacak olan iyileștirme sonucunda aynı risk değeri RÖS=120 olmuş ve orta riskli seviyeye ulaşmıştır.

$\mathrm{Bu}$ çalışmada; risk açısından en yüksek risk değerini alan ana ve/veya alt mekânları öncelikli olarak değerlendirilmiş ve bu bölümler için acil çözüm önerileri oluşturulmuştur. Merdiven ve asansörler için hiçbir önlem alınmadan yapılan Risk tablosundaki çok riskli oranı \%40'dır. Yapılan iyileştirmeler sonucunda ise, RÖS parametrelerinde olasılık ve frekansta değișimler meydana gelmeli, fakat riskin șiddeti aynı kalmalıdır. Tablo 10-11-12-13-14 de Ana grupların alt risk gruplarındaki eski ve iyileştirme sonucu yeni RÖS değerlerinin tabloları özetlemiştir. 
Zerrin Funda Ürük, Didem Yllmaz, Semra Boran, “Özel Kurumlara Ait Huzurevlerinin Mekânsal Risklerinin FineKinney Yöntemi Kullanılarak İncelenmesi: İstanbul Örneği”, İstanbul Gelişim Üniversitesi Sosyal Bilimler Dergisi, 6 (1), Nisan 2019, ss. 102-119

\begin{tabular}{|c|c|c|c|c|c|c|c|c|c|c|c|c|}
\hline & & & & & & & & & \multicolumn{4}{|c|}{ IYILEŞTIRME SONUCU } \\
\hline BÖLÜM ADI & TEHLiKE & RISK/ETKI & $\begin{array}{c}\text { Ş } \\
\text { (şiddet) }\end{array}$ & $\begin{array}{c}0 \\
\text { (olasilık) }\end{array}$ & $\begin{array}{c}F \\
\text { (frekans) }\end{array}$ & $\begin{array}{c}\text { RÖS } \\
\text { (risk } \\
\text { değeri) } \\
\text { (Ş }{ }^{*} \mathrm{O}^{*} \text { ) }\end{array}$ & $\begin{array}{l}\text { RiSKiN SÖZEL } \\
\text { DEĞERI }\end{array}$ & TAVSIYY EDILEN IYILEŞTiRME EYLEMLERI & $\frac{\sqrt[\vec{n}]{\bar{Z}}}{\bar{z}}$ & $\begin{array}{l}\bar{a} \\
\bar{z} \\
\bar{\nu} \\
\end{array}$ & 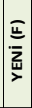 & $\begin{array}{l}\text { YENI } \\
\text { (RÖS) }\end{array}$ \\
\hline \multirow[t]{2}{*}{$\begin{array}{l}\text { MERDIVEN VE } \\
\text { ASANSÖRLER }\end{array}$} & $\begin{array}{l}\text { Basamakların uygun } \\
\text { malzemeden } \\
\text { yapılmaması }\end{array}$ & $\begin{array}{l}\text { Dengesini } \\
\text { kaybederek } \\
\text { düşsme sonucu } \\
\text { ölüm ve ağır } \\
\text { yaralanma }\end{array}$ & 40 & 6 & 6 & 1440 & çok yüksek risk & $\begin{array}{l}\text { Basamakların kaymayan ve kullanıcıaa } \\
\text { uygun malzemeden yapılması }\end{array}$ & 40 & 3 & 1 & 120 \\
\hline & $\begin{array}{l}\text { Basamakların üzerinde } \\
\text { ayak kaymasına karşı } \\
\text { önlem yapılmaması }\end{array}$ & $\begin{array}{l}\text { Dengesini } \\
\text { kaybederek } \\
\text { düşsme sonucu } \\
\text { ölüm ve ağır } \\
\text { yaralanma }\end{array}$ & 40 & 6 & 6 & 1440 & çok yüksek risk & $\begin{array}{l}\text { Basamakların üzerinde ayak kaymasını } \\
\text { önleyici malzemelerden kullanarak } \\
\text { kaymaya karşı önlem yapıl ması }\end{array}$ & 40 & 3 & 1 & 120 \\
\hline & $\begin{array}{l}\text { Merdiven basamakları } \\
\text { doğru ölçüde olmaması } \\
\text { ve basamak aralarııı } \\
\text { eşit mesafede olmaması }\end{array}$ & $\begin{array}{l}\text { Dengesini } \\
\text { kaybederek } \\
\text { düş̧me sonucu } \\
\text { ağır yaralanma }\end{array}$ & 40 & 3 & 3 & 360 & yüksek risk & $\begin{array}{l}\text { Merdiven basamaklarının ve basamak } \\
\text { aralarının standartları uygun oal rak } \\
\text { doğru ölçülere getirilmesiı }\end{array}$ & 40 & 3 & 3 & 360 \\
\hline & $\begin{array}{l}\text { Merdivenden iner veya } \\
\text { çıkarken tutunma barının } \\
\text { yapılmaması }\end{array}$ & $\begin{array}{l}\text { Dengesini } \\
\text { kaybederek } \\
\text { düşsme sonucu } \\
\text { ölüm ve ağır } \\
\text { yaralanma }\end{array}$ & 40 & 3 & 3 & 360 & yüksek risk & $\begin{array}{l}\text { Merdivenden iner veya çıkarken } \\
\text { tutunma barlarının yapılması }\end{array}$ & 40 & 3 & 3 & 360 \\
\hline & $\begin{array}{l}\text { Merdiven } \\
\text { başlangıçlarında metal } \\
\text { konstruksiyondan kilitli } \\
\text { kapı yapıımaması. }\end{array}$ & $\begin{array}{l}\text { Dengesini } \\
\text { kaybederek } \\
\text { düsşme sonucu } \\
\text { ölüm ve ağır } \\
\text { yaral anma }\end{array}$ & 40 & 3 & 6 & 720 & çok yüksek risk & $\begin{array}{l}\text { Katlardaki merdiven başlangıçlarında } \\
\text { metal konstruksiyondan kilitli kapı } \\
\text { yapılması }\end{array}$ & 40 & 0,2 & 0,5 & 4 \\
\hline & $\begin{array}{l}\text { Asansör iç ölçülerinin } \\
\text { sedye ve tekerlekli } \\
\text { sandalye ölçüsüne } \\
\text { uygun yapılmaması. }\end{array}$ & $\begin{array}{l}\text { Acil durumlara } \\
\text { müdahale ve } \\
\text { tahliye güçlüğü }\end{array}$ & 3 & 3 & 6 & 54 & düşük risk & \begin{tabular}{|l} 
Asansör kapısının ve iç ölçülerinin \\
insan ergonomisine, sedye ve \\
tekerlekli sandalye ölçüsüne uygun \\
yeniden düzenlenmesi
\end{tabular} & 3 & 3 & 6 & 54 \\
\hline & $\begin{array}{l}\text { Asansör kapılarının açılış } \\
\text { kapanışlarının zaman } \\
\text { ayarııın yaşıılıara göre } \\
\text { düzenlenmiş olmaması }\end{array}$ & $\begin{array}{l}\text { Acil durumlara } \\
\text { müdahale ve } \\
\text { tahliye güçlüğü, } \\
\text { ölüm, ağır } \\
\text { yaralanma ve } \\
\text { uzuv kaybı } \\
\end{array}$ & 15 & 3 & 3 & 135 & orta risk & $\begin{array}{l}\text { Asansör kapılarının açııı̧ / } \\
\text { kapanışlarının zaman ayarının yaşııııa } \\
\text { göre ayarlanması }\end{array}$ & 15 & 3 & 3 & 135 \\
\hline & $\begin{array}{l}\text { Asansör iç kabininde } \\
\text { telefon düzeninin olması }\end{array}$ & $\begin{array}{l}\text { Acil durumlara } \\
\text { müdahale ve } \\
\text { tahliye güçlüğü }\end{array}$ & 15 & 3 & 2 & 90 & orta risk & $\begin{array}{l}\text { Asansör iç kabininde telefon düzeninin } \\
\text { yada panik butonun yapılması }\end{array}$ & 15 & 3 & 2 & 90 \\
\hline & $\begin{array}{l}\text { Asansörü çal ıştıracak } \\
\text { jeneratörün olmaması. }\end{array}$ & $\begin{array}{l}\text { Acil durumlara } \\
\text { müdahale ve } \\
\text { tahliye güçlüğü }\end{array}$ & 3 & 3 & 2 & 18 & çok düşük risk & $\begin{array}{l}\text { Huzurevinde jeneratör olması ve } \\
\text { çalıştırılacak şekilde sisteminin } \\
\text { kurulması }\end{array}$ & 3 & 3 & 2 & 18 \\
\hline & $\begin{array}{l}\text { Merdiven bölgesinin } \\
\text { aydınlatmasının yeterli } \\
\text { ve etkin olmaması }\end{array}$ & $\begin{array}{l}\text { Dengesini } \\
\text { kaybederek } \\
\text { düşme sonucu } \\
\text { ölüm ve ağır } \\
\text { yaral anma }\end{array}$ & 40 & 3 & 6 & 720 & çok yüksek risk & $\begin{array}{l}\text { Merdiven bölgesinin aydınlatmasının } \\
\text { mekanın ebatına göre yeterli ve etkin } \\
\text { olması için fizibilite çalışmalarııın } \\
\text { yapıl ması ve ona uygun nitelik ve } \\
\text { nicelikte aydınlatma armatürlerinin } \\
\text { yerleştirilmesi }\end{array}$ & 40 & 0,2 & 0,5 & 4 \\
\hline
\end{tabular}

Tablo 10: Merdiven ve Asansörlerin alt risk gruplarındaki eski ve iyileştirme sonucu yeni RÖS değerlerinin tablosu 
Zerrin Funda Ürük, Didem Yllmaz, Semra Boran, “Özel Kurumlara Ait Huzurevlerinin Mekânsal Risklerinin FineKinney Yöntemi Kullanılarak İncelenmesi: İstanbul Örneği”, İstanbul Gelişim Üniversitesi Sosyal Bilimler Dergisi, 6 (1), Nisan 2019, ss. 102-119

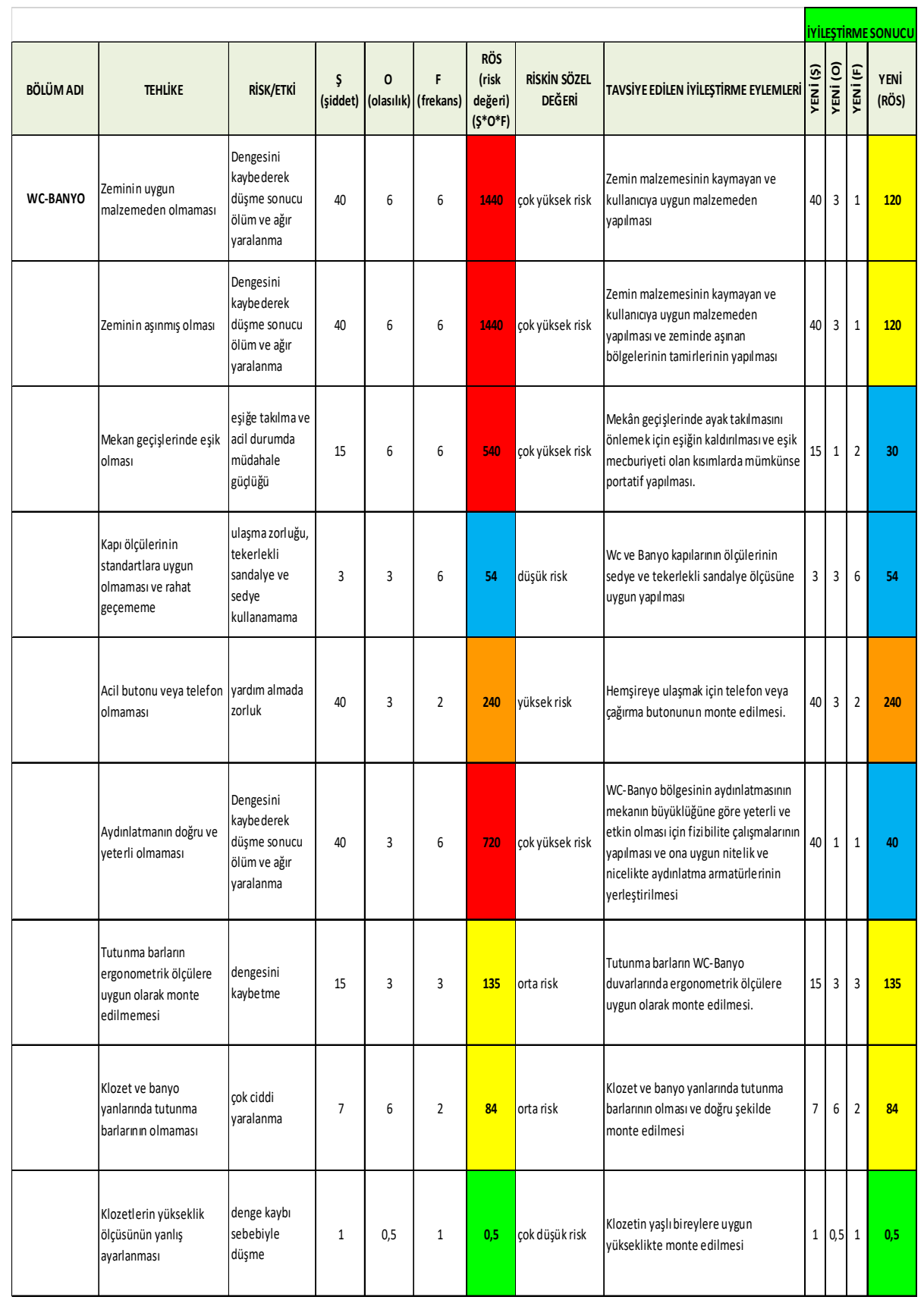

Tablo 11: WC ve Banyo mekânının alt risk gruplarındaki eski ve iyileştirme sonucu yeni RÖS değerlerinin tablosu 
Zerrin Funda Ürük, Didem Yllmaz, Semra Boran, “Özel Kurumlara Ait Huzurevlerinin Mekânsal Risklerinin FineKinney Yöntemi Kullanılarak İncelenmesi: İstanbul Örneği”, İstanbul Gelişim Üniversitesi Sosyal Bilimler Dergisi, 6 (1), Nisan 2019, ss. 102-119

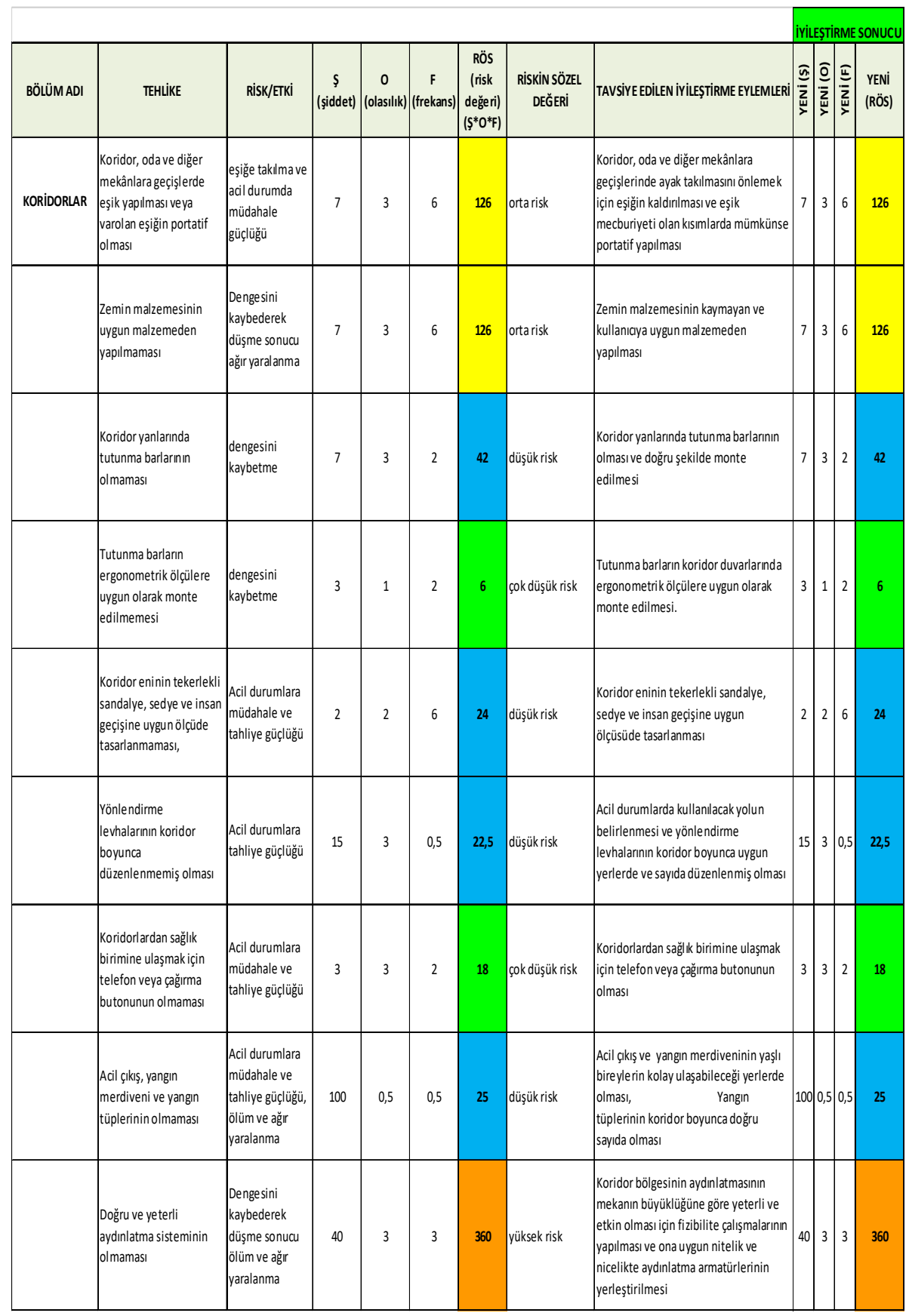

Tablo 12: Koridorların alt risk gruplarındaki eski ve iyileștirme sonucu yeni RÖS değerlerinin tablosu 
Zerrin Funda Ürük, Didem Yllmaz, Semra Boran, “Özel Kurumlara Ait Huzurevlerinin Mekânsal Risklerinin FineKinney Yöntemi Kullanılarak İncelenmesi: İstanbul Örn eği”, İstanbul Gelişim Üniversitesi Sosyal Bilimler Dergisi, 6 (1), Nisan 2019, ss. 102-119

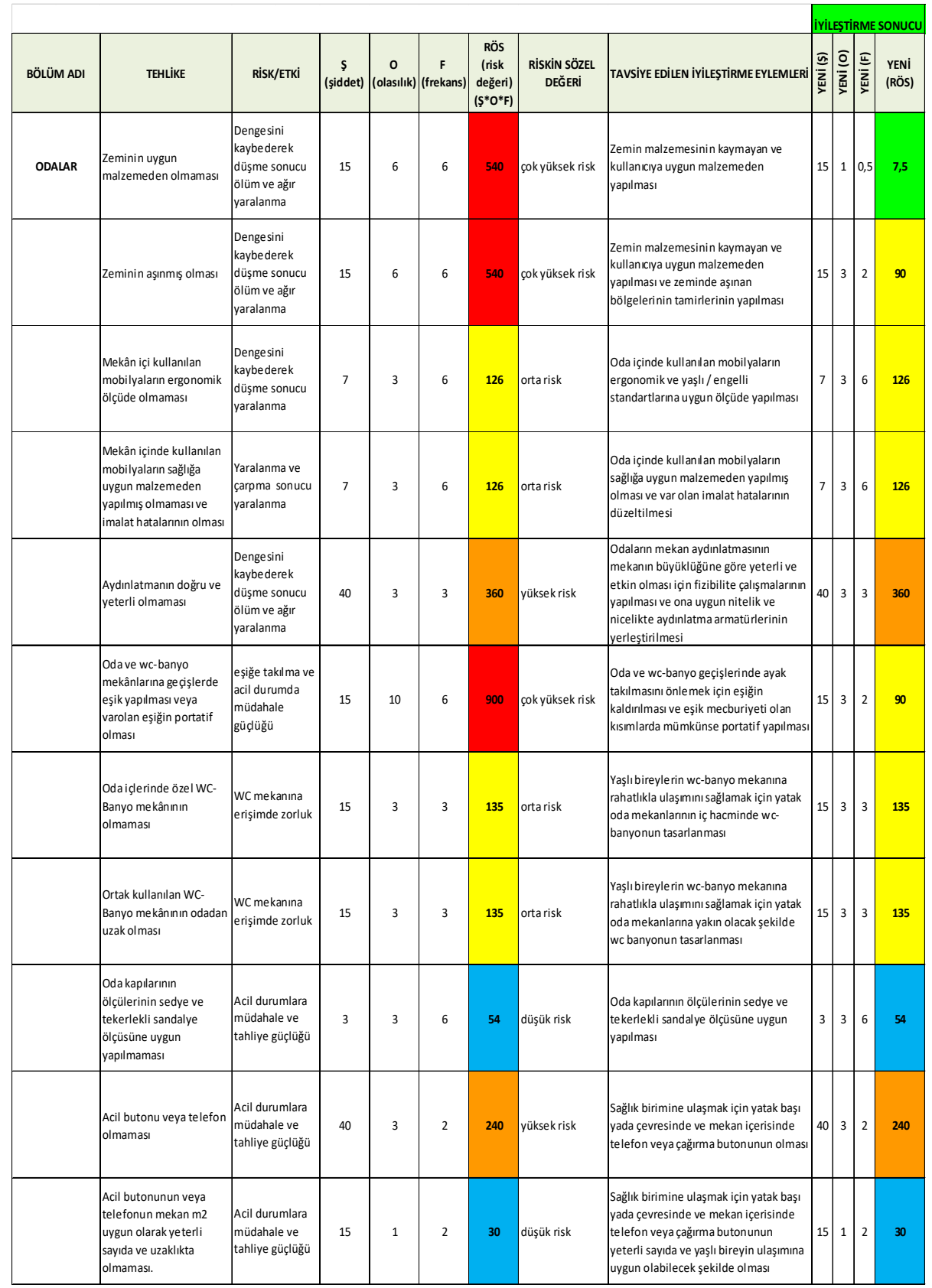

Tablo 13: Odaların alt risk gruplarındaki eski ve iyileştirme sonucu yeni RÖS değerlerinin tablosu 
Zerrin Funda Ürük, Didem Yllmaz, Semra Boran, “Özel Kurumlara Ait Huzurevlerinin Mekânsal Risklerinin FineKinney Yöntemi Kullanılarak İncelenmesi: İstanbul Örn eği”, İstanbul Gelişim Üniversitesi Sosyal Bilimler Dergisi, 6 (1), Nisan 2019, ss. 102-119

\begin{tabular}{|c|c|c|c|c|c|c|c|c|c|c|c|c|}
\hline & & & & & & & & & & & & ONUCU \\
\hline BötüM ADI & TEHLLKE & Risk/ETKi & $\begin{array}{c}\text { s } \\
\text { (siddet) }\end{array}$ & $\left|\begin{array}{c}0 \\
\text { (olasiluk) }\end{array}\right|$ & $\mid \begin{array}{c}F \\
\text { (frekans) }\end{array}$ & 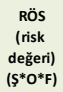 & $\begin{array}{l}\text { RiskiN SÖZEL } \\
\text { DEGEERI }\end{array}$ & TAVSIYE EDiLEN IYILEŞTTRME EYLEMLERi & $\frac{\bar{m}}{\bar{z}}$ & & $\sum_{\underline{W}}^{\frac{\pi}{\omega}}$ & $\begin{array}{l}\text { YENi } \\
\text { (RÖS) }\end{array}$ \\
\hline SOSYAL ALANLAR & $\begin{array}{l}\text { DIs kapının korunakı ve } \\
\text { Kilititi olmaması }\end{array}$ & $\begin{array}{l}\text { Dış kapııdan } \\
\text { kaçma sonucu } \\
\text { olüm, ağır } \\
\text { yaralanma, } \\
\text { düşme }\end{array}$ & 40 & 10 & 2 & 800 & çok yüksek risk & $\begin{array}{l}\text { Diş kapının korunaklıve kilitli sistem } \\
\text { düzeneğinin yapılması }\end{array}$ & 40 & & 0,5 & 20 \\
\hline & \begin{tabular}{|l|} 
Zeminin uygun \\
malzemeden olmaması
\end{tabular} & \begin{tabular}{|l} 
Dengesini \\
kaybederek \\
düssme sonucu \\
ölüm ve ağı̆r \\
yaralanma
\end{tabular} & 15 & 6 & 6 & 540 & çok yüksek risk & $\begin{array}{l}\text { Zemin malzemesinin kaymayan ve } \\
\text { kullaniciya uygun malzemeden } \\
\text { yapılması }\end{array}$ & 15 & 3 & 2 & 90 \\
\hline & Zeminin aşınmış olması & $\begin{array}{l}\text { Dengesini } \\
\text { kaybederek } \\
\text { düsme sonucu } \\
\text { ölüm ve ağıır } \\
\text { yaralanma }\end{array}$ & 15 & 6 & 6 & 540 & çok yüksek risk & $\begin{array}{l}\text { Zemin malzemesinin kaymayan ve } \\
\text { kullaniciya uygun malzemeden } \\
\text { yapılmasıve zeminde aşnan } \\
\text { bölgelerinin tamirlerinin yapılması }\end{array}$ & 15 & 3 & 2 & 90 \\
\hline & \begin{tabular}{|l|} 
Aydinlatmanin doğru ve \\
yeterli olmaması
\end{tabular} & \begin{tabular}{|l} 
Dengesini \\
kaybederek \\
düsme sonucu \\
yaralanma
\end{tabular} & 3 & 6 & 3 & 54 & düşük risk & 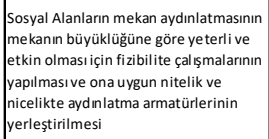 & 3 & 6 & 3 & 54 \\
\hline & \begin{tabular}{|l|} 
Mekân içi kullanilan \\
mobiliyalarn ergon omik \\
ölçüde ol maması
\end{tabular} & $\begin{array}{l}\text { Dengesini } \\
\text { kaybederek } \\
\text { düssme sonucu } \\
\text { yaralanma }\end{array}$ & 7 & 3 & 6 & 126 & orta risk & $\begin{array}{l}\text { Sosyal alanların içinde kullanılan } \\
\text { mobilyaların ergonomik ve yaşı/ı/ } \\
\text { engelli standartlarına uygun ölçüde } \\
\text { yapılıası }\end{array}$ & 7 & 3 & 6 & 126 \\
\hline & \begin{tabular}{|l|} 
Mekân içinde kullanılan \\
mobilyaların sağlı̆ıa \\
uyggun malzemeden \\
yapılmış olmamasıve \\
imalat hatalarinin olması
\end{tabular} & $\begin{array}{l}\text { Yaralanma ve } \\
\text { çarpma sonucu } \\
\text { yaralanma }\end{array}$ & 7 & 3 & 6 & 126 & orta risk & $\begin{array}{l}\text { Sosyal alanların içinde kullanılan } \\
\text { mobilyaların sağlğ̈a uygun } \\
\text { malzemeden yapılmıs olması ve var } \\
\text { olan imalat hatalarının düzeltilmesi }\end{array}$ & 7 & 3 & 6 & 126 \\
\hline & \begin{tabular}{|l|} 
Acil butonu veya telefon \\
olmaması
\end{tabular} & \begin{tabular}{|l|} 
Acil durumlara \\
müdahale ve \\
tahliye güçüğğu
\end{tabular} & 40 & 3 & 1 & 120 & orta risk & $\begin{array}{l}\text { Sağlık birimine ulaşmak için mekan } \\
\text { içerisinde telefon veya çă̈ırma } \\
\text { butonunun yeterli sayıda ve yaşı।ı } \\
\text { bireyin ulaşımına uygun olabilecek } \\
\text { şekilde olması }\end{array}$ & 40 & 3 & 1 & 120 \\
\hline & $\begin{array}{l}\text { Acil butonunun veya } \\
\text { telefonun mekan } \mathrm{m} 2 \\
\text { uygun olarak yeterli } \\
\text { sayida ve uzaklıkta } \\
\text { olmaması. }\end{array}$ & \begin{tabular}{|l|} 
Acil durumlara \\
müdahale ve \\
tahliye güçü̆ğü
\end{tabular} & 7 & 1 & 1 & 7 & çok düşük risk & $\begin{array}{l}\text { Sağılık birimine ulaşmak için mekan } \\
\text { içerisinde telefon veya çă̆ırma } \\
\text { butonunun yeterli sayıda ve yaşı } \\
\text { bireyin ulaşımına uygun olabilecek } \\
\text { şekilde olması }\end{array}$ & 7 & 1 & 1 & 7 \\
\hline
\end{tabular}

Tablo 14: Sosyal Alanların alt risk gruplarındaki eski ve iyileştirme sonucu yeni RÖS değerlerinin tablosu

\section{Sonuçlar}

$\mathrm{Bu}$ çalışmada; İstanbul'daki huzurevlerinde yaşayan toplam 1230 kişinin yoğunlukla kullandıkları mekânsal alanlar üzerinde yapılan incelemeler (Zerrin Funda Ürük ve Didem Yılmaz, kişisel analizler, Nisan 2017) sonucu oluşan risklerin sonuçları Fine-Kinney risk analizi yöntemi ile ortaya konmuş ve öneriler getirilmişti. Gözlemlenen bu durum çerçevesinde aşağıda belirtilen şu sonuçlar elde edilmiştir.

1. Mekânlarda yapılan incelemelerde; 5 ana risk grubu ve bu ana risklerin toplam 47 alt risk grubu tespit edilmiştir.

2. 5 ana risk grubunda incelenen mekânsal alanların risk açısından \%30'u (14/47) iki en riskli alan üzerinde görülmüștür. Bu alanların \%17'si (8/47) sadece WCBanyo ve Merdiven-Asansör de görülmüștür. 
3. Fine-Kinney yöntemi ile bu 5 ana mekânların alt bölgeleri değerlendirilmiş ve 47 alt bölge için 14 bölge ÇOK RİSKLİ konumunda bulunmuştur.

$\begin{array}{llc}\text { Merdiven-Asansör } & 10 \text { alt bölge içinde, } 4 \text { tanesi } & \text { ÇOK RISKLLI } \\ \text { Wc-Banyo } & 9 \text { alt bölge içinde, } 4 \text { tanesi } & \text { ÇOK RISKLLI } \\ \text { Odalar } & 11 \text { alt bölge içinde, } 3 \text { tanesi } & \text { ÇOK RISKLİ } \\ \text { Sosyal Alanlar } & 8 \text { alt bölge içinde, } 3 \text { tanesi } & \text { ÇOK RISSLİ } \\ \text { Koridorlar } & 9 \text { alt bölge içinde, } 0 \text { tanesi } & -\end{array}$

4. Çok Riskli olan bölgeler için (RÖS $\geq 400$ olan değerler için) yeniden yapılan iyileştirme sonucu risk değerleri RÖS $\leq 400$ düşürülmesi hedeflenmiştir.

5. Ele alınan ana risklerin oluşturduğu alt risk gruplarının (tehlike tanımı) her biri için alınması gereken önlemler mekânlar için tespit edilmiş ve eksikliği olan mekânlar için öneriler sunulmuştur.

6. Yapılan yeni iyileștirmeler sonucu RÖS $\geq 400$ olan değerler tamamen iyileştirilmiş ancak diğer iyileştirilmeyen durumlar en riskli konuma dönüşmüştür. Bundan sonraki yeni iyileștirmeler ise buradan başlanmalıdır.

7. Elde edilen sonuçlardan huzurevleri ile ilgili uluslararası standartlara bağ $\mathrm{l}_{\iota}$ ama kültürel normlara sadık kalınarak yeni bir yönetmelik üzerinde çalışılması önerilmektedir.

\section{KAYNAKÇA}

Devlet Planlama Teşkilatı (DPT). (2007), Türkiye'de yaşlıların durumu ve yaşlanma ulusal eylem planı. Erişim tarihi: 25.08.2018, https://sgb.saglik.gov.tr/ Dkmanlar/T\%C3\%BCrkiye\%27de\%20Ya\%C5\%9Fl\%C4\%B1lar\%C4\%B1n\%20Durumu \%20ve\%20Ya\%C5\%9Flanma\%20Ulusal\%20Eylem\%20Plan\%C4\%B1.pdf

DOĞAN BULUT, Z. (2014). Huzurevlerinde ve evde yaşayan yaşlllarda düşme ile ilişkili risk faktörleri. (Yayımlanmış Yüksek Lisans Tezi), T.C. Hacettepe Üniversitesi Sağlık Bilimleri Enstitüsü, Ankara

ERKAL, S. (2005). Kırıkkale Ovacık mahallesinde yaşayan 65 yaş ve üzeri kişilerin ev kazaları ile karşılaşma durumlarının ve kaza nedenlerinin incelenmesi. Türk Geriatri Dergisi, 8(1): 17-21.

KUTSAL GÖKÇE, Y. (2009). “Yaşlanan Dünyanın Yaşlanan İnsanları” GEBAM Yayınları, Ankara. Erişim tarihi: 25.08.2018, http://e-kutuphane.teb.org.tr/pdf/ tebakademi/geriatri 2009/5.pdf

LÖK, N. \& AKIN, B. (2013, Şubat). Domestic environmental risk factors associated with falling in elderly. Iranian Journal of Public Health, 42(2):120-128.

MUMCU BOĞA, N., ÖZDELİKARA, A. \& AĞAÇDİKEN, S. (2015, Ocak). Huzurevindeki yaşlı hastalarda düşme davranışlarının belirlenmesi. Gümüşhane Üniversitesi Sağlık Bilimleri Dergisi, 4(3): 360-372

PÜLÜM, E., SÖKMEN, Ü.N., ÇEVIK AKYIL, R., ONGUN, G. \& ÖZDEMİR CIHHANGİR, H. (2018, Ocak). Aydın Huzurevinde Düşme Riski Taşıyan Yaşlıların Belirlenmesi: 
Tanımlayıcı Çalışma. İzmir Kâtip Çelebi Üniversitesi Sağlık Bilimleri Fakültesi Dergisi, 3(2): 9-14

TC. Aile ve Sosyal Politikalar Bakanlığı, (2016), Türkiye'de yaşlı bakım hizmetlerinin proaktif yönü ve mali yükü analizi etüt araştırması. Erişim tarihi: 25.08.2018, https://ailetoplum.aile.gov.tr/uploads/pages/indirilebilir-yayinlar/83turkiye-de-yasli-bakim-hizmetlerinin-proaktif-yonu-ve-mali-yuku-analizi-etutarastirmasi-2016.pdf

TC. Aile ve Sosyal Politikalar Bakanlığı, (2012), Yaşlanma 2002 uluslararası eylem planı, Erişim tarihi: 25.08.2018, https://eyh.aile.gov.tr/yaslanma-2002-uluslararasieylem-plani

T.C. Kalkınma Bakanlığı, Onuncu kalkınma planı 2014-2018, yaşlanma özel ihtisas raporu. Erişim tarihi: 25.08.2018, http://www.kalkinma.gov.tr/Lists Lzel\%20htisas\%20Komisyonu\%20Raporlar/Attachments/248/Ya\%C5\%9Flanma\%20 \%C3\%96zel\%20\%C4\%B0htisas\%20Komisyonu\%20Raporu.pdf

Türkiye İstatistik Kurumu (TÜİK). (2014), İstatistiklerle yaşlılar, 2013, Erişim tarihi: 25.08.2018, http://www.tuik.gov.tr/PreHaberBultenleri. do?id=16057

Türkiye İstatistik Kurumu (TÜİK). (2017), Yıllara, yaş grubu ve cinsiyete göre nüfus, 1935-2017, Erişim tarihi: 25.08.2018, http://www.tuik.gov.tr/PreIstatistikTablo.do?istab id=1588

World Health Organization (WHO). (2015), Ageing and health, Erişim tarihi: 25.08.2018, http://www.who.int/en/news-room/fact-sheets/detail/ageing-and-health

World Health Organization (WHO). (2015), Populations are getting old, Erişim tarihi: 25.08.2018, http://www.who.int/ageing/events/world-report-2015launch/populations-are-getting-older-full.gif?ua=1

\section{Summary}

As in the world, the rapidly aging population in Turkey and the problems in the elderly population is increasing proportionally accordingly. The importance of institutions such as nursing homes serving for housing and care, which is one of the most important problems of elderly people, and the fact that they provide services in accordance with world standards are gaining importance in our country. For this reason, elderly nursing homes and care homes were discussed in this study. The fastest growing elderly group in the world is 80 years and older. In 2000, the number of elderly people in this group is 70 million, while this number is expected to increase by 5 times over the next 50 years. All developed countries will face the aging of their populations in the following years. As the World Health Organization (2015) stated; it is foreseen that the elderly population will start a process called "aging of the elderly".

According to the World Health Organization (WHO) chronological classification; the age range 60-75 is considered as senior age, and between 75-89 years elderly age and very old age limit is 90 and above. When the United Nations defines a country as an "elderly" population; it points out that the elderly population in that country is between $8 \%$ and $10 \%$ according to the general population ratio. According to the 2016 population 
of Turkey Statistical Institute data; It has been observed that the rates of persons over 65 years of age have reached $8.3 \%$. In the researches, the rate of meeting the daily care needs of elderly people between the ages of 65-69 is 5\% and below, and the rate of daily care needs can be increased to $30 \%$ in people aged 80 and over. Nursing homes are the places where the elderly people are provided for their daily needs, as well as socialization, health and treatment facilities. Therefore, the quality of the nursing homes is an indication of the quality of life of the elderly. However, the research shows that these services offered to maintain the quality of life of the elderly are not very adequate in these centers.

In this context, 29 nursing homes belonging to private institutions were examined within the scope of Istanbul province, and the data obtained from the institutions or identified in one-to-one places were examined in situ. During this period, 1230 elderly individuals in the institutions have been studied and the spatial risks that they are exposed to / can be exposed to were discussed and evaluated. In this sample, 869 women and 361 men were elderly. Elderly individuals in nursing homes and care homes were found to be between 68.1-79.7 years of age. As a result of the investigations carried out in nursing homes, the places frequently used by the elderly population were identified and the locations that could cause an estimated risk were grouped in 5 main groups. These groups; stairs / elevators, wc / bathrooms, corridors, rooms and social areas are defined as. For these areas, 47 sub-risk groups were determined and each of these sub-risks were found to be Fine-Kinney Risk Analysis Method and Risk Priority (ROS) parameter. Fine-Kinney Method is a quantitative method that can make predictions of correct and error-free future by using historical data of institutions. Evaluation of Fine-Kinney Risk Analysis Method consists of probability, violence and frequency scales. These scales are obtained by multiplying with each other. Risk priority number (ROS) is an important parameter in grouping risks. When this method was applied to the problem, 30\% of the spatial areas examined in the 5 main risk groups were observed on the two most risky areas. $17 \%$ of these areas are concentrated in WC-Bath and Stair-Elevators. The highest risk value (ROS) is the area and indicated by red; Stairs-Lifts 4 parts, WC-Bathroom 4 parts, 0 parts in the Corridors, 3 parts in the Rooms and 3 parts in the Social areas are the important categories of the need for improvement studies have emerged.

As a result of the study, the measures that should be taken for each of the sub-risk groups (hazard definition) formed by the main risks discussed in order to improve the living standards of the elderly people living in the nursing homes in Istanbul, were determined for the spaces and suggestions for the spaces that are lacking were presented. Based on the results obtained, it is recommended to work on a new regulation in accordance with the international standards regarding nursing homes, but in accordance with cultural norms. 